\title{
EDUCANDO PARA A SUSTENTABILIDADE: OPINIÃO DOS ESTUDANTES DA UFSM SOBRE ENERGIA SOLAR
}

\author{
José Ayrton de Souza Borne Junior* ${ }^{1,}$ Damaris Kirsch Pinheiro** \\ ${ }^{1}$ Eng $^{0}$. Eletricista - PROINFRA - UFSM. ayrton.jose@smail.ufsm.br \\ ** Prof $^{\mathrm{a}}$. Dr ${ }^{\mathrm{a}}$. Eng ${ }^{\mathrm{a}}$. Química - DEQ - UFSM - Diretora do LACESM/UFSM: damariskp@gmail.com
}

\section{RESUMO}

Com este artigo procura-se mostrar a opinião de estudantes, beneficiários de um programa de ajuda socioeconômica para carentes da UFSM e de agora em diante nomeados público-alvo, acerca da utilização da energia solar e outras energias renováveis e que responderam um questionário acerca do assunto. $\mathrm{O}$ mesmo foi acompanhado de um folder explicativo durante a abordagem. Como se trata de uma pesquisa descritiva, na qual o público-alvo manifesta a sua opinião ante as perguntas propostas, as respostas foram tabuladas de forma gráfica e em quadros, mostrando a percentagem relativa em cada questão, seguindo-se uma análise das mesmas. Chegando a conclusão de que o público-alvo tem um conhecimento sim de energias renováveis e que apoiam em sua integralidade a implantação e a utilização de um Sistema de Aquecimento Solar de água em seu local de moradia.

Palavras-chave: Educação ambiental. Energias renováveis. Energia solar.

\section{INTRODUÇÃO}

A educação ambiental deve ser um processo contínuo, atuante e metamórfico, no sentido de se adaptar as diversas situações que se Ihe apresentam e buscando se adequar as inúmeras exigências de uma sociedade que não respeita as complexidades do meio ambiente e que, no entanto, necessita dele para sobreviver. Neste estágio atual, prima-se por investir nas gerações atuais que estão nas escolas, universidades e outras formas de ensino para que atentem para as necessidades ambientais e, para não dizer, a manutenção da vida humana.

$\mathrm{Na}$ continuação, apresentam-se os resultados de uma pesquisa realizada com estudantes universitários sobre a opinião que eles manifestam acerca de: educação ambiental, utilização da energia solar, outras formas de energias renováveis, o Sol e a abordagem do tema nos cursos oferecidos pela universidade. Espera-se com isto uma contribuição a um tema que é bastante comentado, mas em relação a sua prática muito deficiente, a preservação do meio ambiente. 


\section{EDUCAÇÃO AMBIENTAL}

O Brasil, como nação, deixa bem claro em sua carta magna, a Constituição Federal Brasileira de 1988, no seu Título VIII, Da Ordem Social, no Capítulo VI, Do Meio Ambiente, em seu artigo número $225, \S 1$ 을 no item VI que cabe ao poder público "promover a educação ambiental em todos os níveis de ensino e a conscientização pública para a preservação do meio ambiente", ou seja, que a educação ambiental é um dever do poder público a sua disseminação e que todos têm direito ao seu acesso.

A educação ambiental também pode ser definida como:

um processo contínuo e permanente que busca a transformação de valores e atitudes e posicionamentos pelos quais, a comunidade por intermédio do indivíduo esclarece conceitos voltados para a conservação do ambiente (NOGUERA, 2004, s/n).

Sendo um processo contínuo, há necessidade de que seja constantemente transmitido e disseminado em todos os níveis educacionais e civis de nossa sociedade.

\section{$20 \mathrm{SOL}$}

Segundo a The Cambridge Encyclopedia of the Sun (LANG, 2001) o Sol é uma estrela de $5^{\text {a }}$ grandeza e, como tantas outras estrelas, é muito massiva. Possui 109 vezes o tamanho do diâmetro da Terra e 333.000 vezes a sua massa. O Sol tem uma densidade inferior a da Terra, ou massa por unidade de volume. A densidade média do Sol é de $1409 \mathrm{~kg} / \mathrm{m}^{3}$, o qual é a quarta parte da densidade média da Terra.

A luz do Sol leva cerca de 8 minutos para alcançar a Terra. Para determinar a quantidade de energia solar que alcança quase todo centímetro quadrado da Terra a cada segundo, pode-se utilizar a constante solar, $\mathrm{f}_{\odot}\left(1366 \mathrm{~W} / \mathrm{m}^{2}\right)$, e a distância média do Sol a Terra $\left(1.4959787 .10^{11} \mathrm{~m}\right)$. Então, utilizando a equação 1 :

$$
\begin{aligned}
& L_{\Theta}=4 . \pi \cdot f_{\Theta} \cdot(A U)^{2}=4 . \pi \cdot 1366^{\mathrm{W}} / \mathrm{m}^{2} \cdot\left(1.4959787 .10^{11} \mathrm{~m}\right)^{2}=3.854 .10^{26} \mathrm{~W} \\
& L_{\Theta}=3.854 .10^{26} \mathrm{~J} / \mathrm{s}
\end{aligned}
$$

\section{CAPTAÇÃO DA ENERGIA SOLAR}

Atualmente existem muitas formas de utilizar o Sol para gerar energia, entre as quais podemos citar:

3.1 sistema fotovoltaico: sistema de acumulação de energia utilizando módulos em painéis fotovoltaicos e que, ao invés de utilizar a energia solar para aquecimento da água, por exemplo, a utiliza para gerar tensões elétricas. Normalmente estes módulos, ou células, fotovoltaicos são fabricados com semicondutores;

3.2 geração termos solar: processo que converte energia solar em energia térmica e esta, por sua vez, é convertida em energia elétrica. Este processo de conversão é realizado em quatro etapas: coletor, receptor, transporte e armazenamento e conversão elétrica e 
3.3 sistema de aquecimento de fluido: funciona como um trocador de calor através das seguintes etapas: captação da energia solar, transferência da energia para o fluido, armazenamento da energia térmica e distribuição da água aquecida para o sistema.

\section{METODOLOGIA}

A metodologia constou de duas etapas: confecção de um folder explicativo sobre o funcionamento de coletores solares e aplicação de um questionário sobre o conhecimento e o uso de energias alternativas.

Foi realizada uma pesquisa de campo descritiva através de uma técnica padronizada de coleta de dados (questionário (APÊNDICE A) e folder explicativo (APÊNDICE B), sendo os dados posteriormente analisados de forma quantitativa (respostas traduzidas em números e a utilização de técnicas estatísticas para análise)). Os objetivos da aplicação do questionário são: informações pessoais (idade, curso, tempo de moradia na CEU, etc.) sem a necessidade de identificação de quem forneceu a resposta, conhecimento de fontes de energia alternativas, o Sol como fonte de energia e a aplicação e $\mathrm{o}$ uso de fontes de energia sustentáveis. $O$ folder tem como função fornecer uma visão resumida e clara sobre as vantagens da utilização da energia solar em relação aos tipos de energia convencionais e traz em seu arcabouço informações úteis para iniciar ao público-alvo com uma base para um futuro aprofundamento no assunto, quem sabe em nível de pós-graduação. Também traz um resumo do funcionamento de um Sistema de Coletores Solares para o aquecimento da água, com informações de como este fenômeno físico se realiza.

\section{RESULTADOS E DISCUSSÕES}

Da população de 135 estudantes aos quais foi fornecido o conjunto (questionário + folder), uma amostra ${ }^{2}$ de 50 estudantes devolveu o mesmo preenchido, o que corresponde a $37 \%$ da população. Destes resultados obtidos, há números interessantes os quais se cita:

- a média de idade dos estudantes que responderam ao questionário é de 22 anos, ou seja, estão inseridos nos 14,4\% dos brasileiros de 18 a 24 anos, com mais de 11 anos de estudo, e que estão entrando em um curso superior ainda em uma idade muito alta, segundo dados do relatório PNAD 2010 (IBGE, 2010, s/n);

- para corroborar a amostra de 50 estudantes que devolveram os questionários

preenchidos e para validar os dados referentes à idade do público-alvo que respondeu ao mesmo, foi utilizada uma distribuição de probabilidade qui-quadrado, a qual forneceu:

Utilizan um erro de 2,5\%, tem-se uma probabilidade de $36,8 \%$, o que fornece: Número de amostras $=\$ 5035.36,8 \%) / 100$

${ }^{2}$ É um subconjunto de uma população. A amostra deve ser obtida de uma população específica e homogênea por um processo aleatório. A aleatoriedade é condição necessária para que a amostra seja representativa da população. 
Ou seja, corroborando a validade da amostra referente aos dados relativos à idade do público-alvo. Portanto, teve-se uma faixa de idade entre 19 e 25 anos correspondente ao público-alvo que respondeu ao "Questionário do conhecimento";

- para a média do tempo de moradia na CEU também foi utilizada uma distribuição quiquadrado, a qual forneceu:

=

Utilizando a tabela de distribuição $x^{2}$ com graus de liberdade igual a 29 e um erro de $10 \%$, tem-se uma probabilidade de $39,1 \%$, o que fornece:

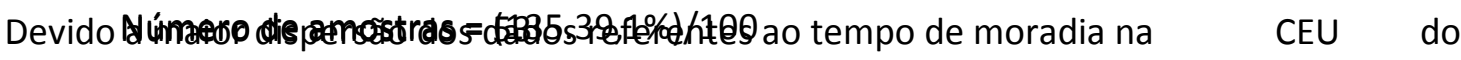
público-alvo e para corroborar a amostra escolhida foi necessário aumentar o erro e mesmo assim, obteve-se um valor próximo a amostra. Utilizando uma taxa percentual maior de erro, conforme a tabela de distribuição $x^{2}$, obtém-se um valor de amostra inferior ao escolhido (com um erro de $25 \%$ obteve-se um valor de 45 amostras).

Portanto, tivemos uma faixa de 12 meses ( 1 ano) a 46 meses ( 3 anos e 10 meses) correspondente ao tempo de moradia do público-alvo que respondeu ao "Questionário do conhecimento";

- 91\% dos estudantes que responderam ao questionário provêm de cidades no estado do Rio Grande do Sul e os restantes $9 \%$ vêm de outros estados da federação, o que evidencia que a UFSM é uma universidade que é buscada como uma opção para estudantes de diversas localidades do país, mas que seu principal público a ser atendido na graduação e pósgraduação continua sendo do estado do Rio Grande do Sul, também devido à distância e localização no interior do estado;

A análise do questionário é realizada através das respostas fornecidas a cada questão pela amostragem do público-alvo no "questionário do conhecimento". Muitas das questões tiveram mais de uma resposta dada pelos estudantes e todas elas foram levadas em conta nesta análise. No presente vamos relatar as questões mais relevantes em seu aspecto educacional e ambiental, foco deste artigo.

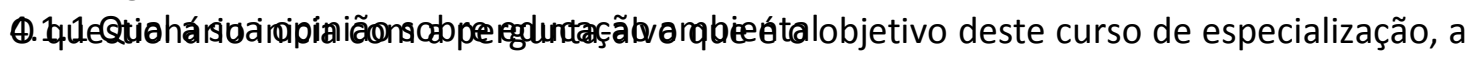
compreensão, para o estudante, do que seja a educação ambiental. As respostas, bem como a sua porcentagem em relação ao todo, estão dispostas na Figura 1. 

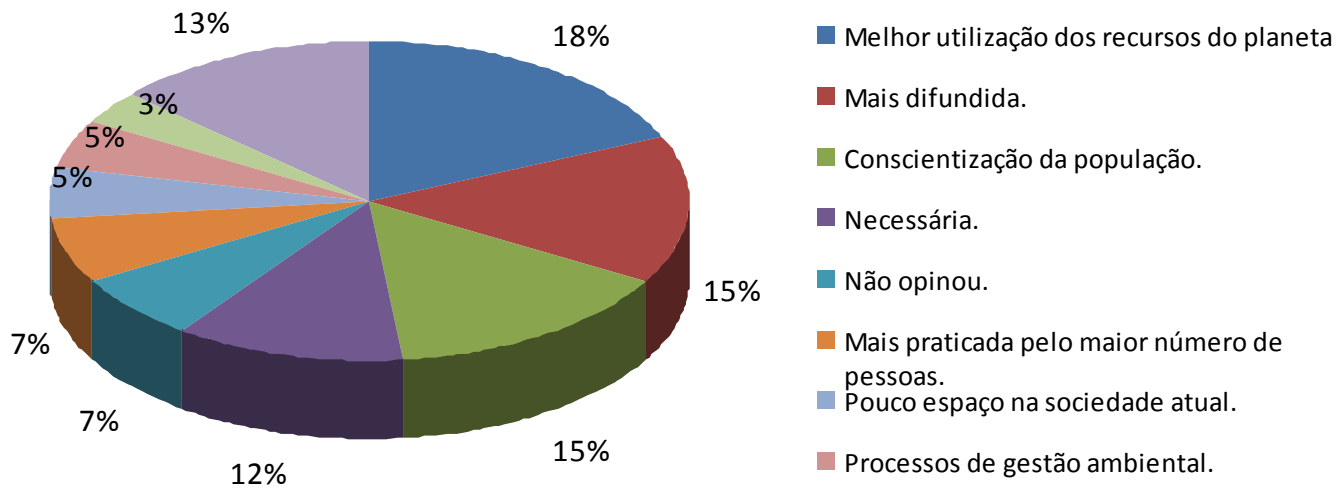

Figura 1: gráfico da porcentagem relativa às respostas da questão 1 do "Questionário do conhecimento" (BORNE, 2011, s/n).

Fica evidente pelas respostas apresentadas que, para a maioria dos estudantes, a educação ambiental deve garantir o futuro das próximas gerações através da divulgação e conscientização da população, que isto é uma necessidade e deve ser uma prática do maior número de pessoas. Há um forte sentido de verdade neste fato, pois apesar da educação ambiental estar focada e bem incentivada na constituição federal brasileira, há pouco conhecimento e muito pouca divulgação. Prova deste fato são as opções "Não opinou" e "Tem pouco espaço na sociedade atual" como respostas fornecidas ao questionário; ele possui a clara visão de que em nossa sociedade a educação ambiental é mais uma questão de ser "ambientalmente" e "socialmente correto" do que colocar em prática. Isto é uma mensagem preocupante para uma sociedade, como a brasileira, que almeja um futuro valorizando a sua natureza.

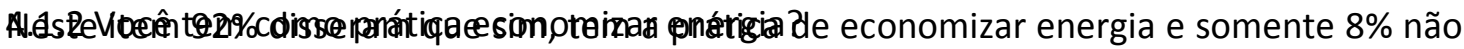
tomou como hábito a economia de energia.

Este é um dado positivo, pois a maioria dos estudantes entende que economizar energia é um fator determinante para a manutenção dos recursos ambientais e que habitando em comunidade em um lugar que não lhes pertence, somente durante o curso, podem economizar os gastos do poder público nas contas de energia.

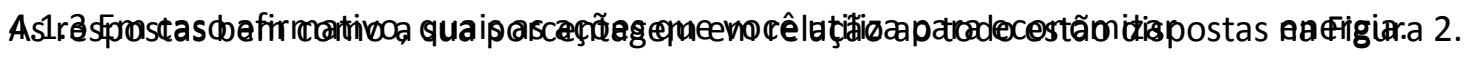




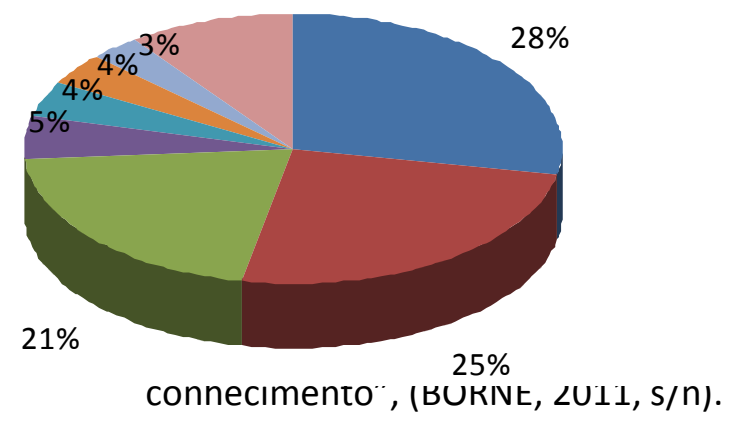

Desligar lâmpadas.

- Diminuir o tempo no banho.

- Desligar equipamentos.

Utilizar lâmpadas econômicas.

- Utilizar luz ambiente.

- Evitar manter lâmpadas acesas.

- Fechar torneiras.

Outras respostas

io do

Dos $92 \%$ dos estudantes que responderam afirmativamente que tem como prática economizar energia, todos citaram tarefas práticas para tornar este fato em realidade. Ações como diminuir o tempo do banho, desligar equipamentos que não estão sendo utilizados e utilizar lâmpadas econômicas revelam ações em prol da economia de energia. Desligar lâmpadas na ausência de pessoas e fechar as torneiras quando não utilizadas lembram campanhas do governo em momentos nos quais havia uma menor oferta de energia pelo poder público e em momentos de falta de chuva em regiões brasileiras e no estado do Rio Grande do Sul, isto mostra que realmente a propaganda influencia quando bem direcionada em prol do meio ambiente e interesses econômicos governamentais. Uma grata surpresa foi à citação da utilização da luz ambiente, o que revela uma educação ambiental no sentido de economia ao utilizar a luz solar ao invés de consumir a luz artificial.

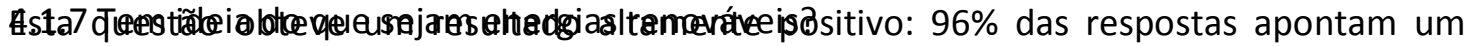
conhecimento do que sejam energias renováveis, que são aquelas que não poluem o meio ambiente e que, como o nome diz, estão disponíveis em todos os novos dias. Aponta para um começo muito auspicioso de educação ambiental nos estudantes que buscam um conhecimento superior e que podem realmente influenciar na utilização de novas formas de energia, inovando e não somente utilizando energias provenientes de fontes fósseis e altamente poluidoras, formadoras de gases do efeito estufa e instabilizando o clima.

4.1.9 Em sua opinião, quais formas de energia hoje utilizadas poderiam ser substituídas por alguma forma de energia renovável.

Esta questão gerou uma série de sugestões plausíveis e de aplicação, senão imediata, pelo menos em médio prazo. Destaca-se a efetiva participação dos estudantes, já que este é um tema concernente à educação ambiental, pois visa à diminuição da emissão de gases do efeito estufa por energias não renováveis.

Para uma análise inicial seria realmente interessante observar a Figura 3 para uma posterior discussão. 

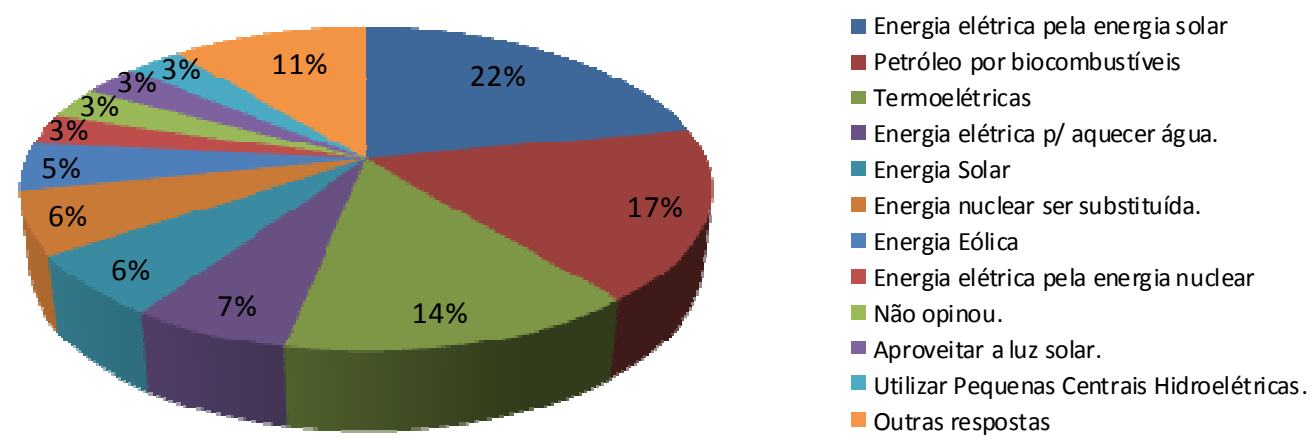

Figura 3: gráfico da porcentagem relativa às respostas da questão 9 do "Questionário do conhecimento", (BORNE, 2011, s/n).

É possível perceber que respostas significativas e inseridas no contexto da questão apareceram e representaram a maioria daquelas fornecidas pelos estudantes. A substituição da energia elétrica pela energia solar e a substituição do uso do petróleo por biocombustíveis são as que alcançaram maior escolha. A primeira porque é um tipo de energia não poluente e a segunda devido à intensa campanha do governo, nos últimos anos, pelo uso dos biocombustíveis em substituição aos hidrocarbonetos insaturados representados pelo óleo e a gasolina. A efusão das plantações de cana-de-açúcar e o investimento pesado de empresas como a PETROBRAS têm sido os ícones da impulsão deste tipo de energia renovável, o que influenciou, bastante, esta resposta por parte dos estudantes.

A citação da energia termoelétrica revela também uma preocupação salutar da comunidade estudantil pelo investimento pesado sendo realizado pelo estado do Rio Grande do Sul na área da queima do carvão para a geração de energia elétrica, o que representa uma carga a mais de poluentes a ser jogado na atmosfera na região de Candiota e por ação do vento espalhando-se pelo estado gaúcho.

Novamente a energia nuclear é citada e de uma forma dicotômica, com dois lados: o positivo na substituição da energia elétrica pela nuclear e o lado negativo solicitando a sua substituição pelos riscos que oferece. Este antagonismo é extremamente salutar e demonstra a capacidade que os estudantes possuem de reativar discussões através de opiniões divergentes sobre a mesma forma de energia.

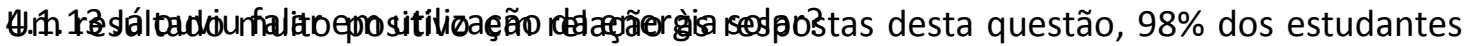
respondeu que já ouviram falar na utilização da energia solar. É um número revelador e mostra um amadurecimento para se começar a utilizar energias renováveis na UFSM, como um braço da educação ambiental.

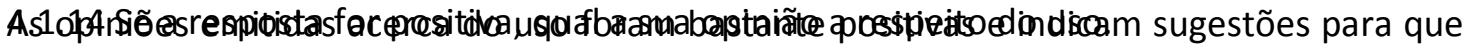
melhor se consiga aproveitar a energia que vem do Sol em aplicações práticas e econômicas.

Uma visão das respostas fornecidas pode melhor ser observada através da Figura 4. 


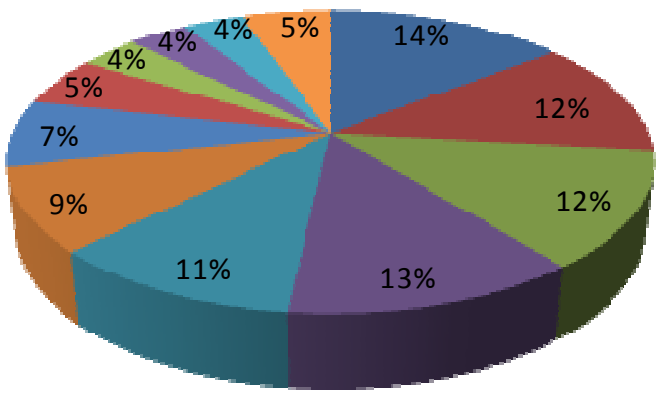

\author{
- Diminuir o custo da energia. \\ - Muito interessante e importante. \\ - Educadora ambiental. \\ - Deveria ser mais explorado. \\ - Diminui o consumo. \\ - Interessante desde que seja viável. \\ - Custo muito alto de instalação. \\ - Disponibilização para a população. \\ útil. \\ Diminuir os danos ambientais. \\ - Não opinou. \\ - Outras respostas
}

Figura 4: gráfico da porcentagem relativa às respostas da questão 14 do "Questionário do conhecimento", (BORNE, 2011, s/n).

4.1.19 Além da utilização da energia solar como aquecimento, você conhece mais alguma forma de utilização deste tipo de energia?

Em termos de aplicação ficou bastante restrito somente ao aquecimento. $62 \%$ dos estudantes não conhecem outra forma de utilização da energia solar, $36 \%$ já ouviram e/ou presenciaram outras maneiras do uso de sistemas solares e $2 \%$ não opinaram acerca do assunto. Esta grande disparidade e ao mesmo tempo esta pobreza cultural e ambiental referente ao uso de energias renováveis deve-se a pouca disseminação do assunto na universidade.

4.1.21 O folder explicativo sobre Energia Solar de alguma forma Ihe ajudou a compreender o que é uma energia renovável e qual a sua utilização?

O principal objetivo de alguém que se propõe a realizar um material educativo ou que forneça alguma informação importante deve ser a clareza, a facilidade de entendimento e a objetividade. Estas características também estavam no alvo ao se realizar o folder de educação ambiental sobre energias renováveis, em especial a energia solar. A partir disto, o retorno do público-alvo para o qual se destina o material, também é uma informação importante, para ver se o objetivo para o qual foi feito foi alcançado.

É o que se pode verificar no Quadro 1 a partir das observações dos estudantes recolhidas do "Questionário do conhecimento". 


\begin{tabular}{|c|l|c|}
\hline ITEM & & RESPOSTA NO QUESTIONÁRIO \\
\hline 1 & Sim. & $77 \%$ \\
\hline 2 & Não ajudou muito. & $6 \%$ \\
\hline 3 & Ainda não li o folder. & $2 \%$ \\
\hline 4 & Está bem resumido, mas possui uma explicação satisfatória. & $2 \%$ \\
\hline 5 & A figura estava com detalhes apagados. & $2 \%$ \\
\hline
\end{tabular}

Quadro 1 - O folder explicativo sobre energia solar de alguma forma lhe ajudou a compreender o que é uma energia renovável e qual a sua utilização? (BORNE, 2011, s/n).

Após a análise destes dados, pode-se concluir que o folder cumpriu a sua função informativa e esclarecedora fornecendo uma boa introdução sobre a energia solar. Uma sugestão de melhoria seria uma melhor qualidade da figura no verso que estava com os detalhes apagados e uma versão mais aprofundada do texto.

Como um lema em relação à educação ambiental, criaram-se as duas frases abaixo para estarem presentes como uma lembrança da responsabilidade não só do poder público, mas de cada um de nós, de cada brasileiro e em um campo mais restrito, da comunidade acadêmica da UFSM no sentido do engajamento na educação pela sustentabilidade e na preservação consciente do meio ambiente.

Educação Ambiental está na constituição brasileira, é um dever de todos e um direito do brasileiro de hoje e do amanhã.

Energia Solar - Uma UFSM sustentável - Porque não? Apoie essa ideia.

\section{CONCLUSÃO}

Utilizou-se como público-alvo deste trabalho estudantes que possuem benefício socioeconômico e que por este motivo habitam na Casa do Estudante Universitário da UFSM. Demonstrou-se que é possível sim educar para a sustentabilidade através da utilização de sistemas que utilizam energias renováveis e que esta ação ficou bem clara com a elaboração e a utilização do folder sobre energia solar, não só evidenciando as possíveis utilizações deste tipo de energia não poluente, como também criar um comportamento econômico em relação aos meios naturais e energéticos; isto ficou evidente com o entendimento e a aceitação do folder através do "Questionário do conhecimento". 
O "Questionário do conhecimento" proporcionou, também, uma via para que o públicoalvo possa tomar consciência do meio ambiente e esta ação foi despertada através das respostas fornecidas às questões propostas. Demonstrou uma maturidade para a utilização da energia solar, o apoio ao projeto proposto e a sua concretização, a instalação de um Sistema de Aquecimento Solar na CEU, e o retorno a, ou descoberta, que o Sol tem uma energia radiante que está disponível para utilização, seja de forma imediata ou em médio e longo prazo.

\section{REFERÊNCIAS BIBLIOGRÁFICAS}

FONSECA, Jairo Simon da, MARTINS, Gilberto de Andrade. Curso de Estatística. 6a edição. São Paulo: Atlas, 2009.

IBGE. Síntese de Indicadores Sociais: uma análise das Condições de Vida da População Brasileira 2010. Rio de Janeiro, 2010.

LANG, K. R. The Cambridge Encyclopedia of the Sun. Cambridge: Cambridge University Press, 2001.

NOGUERA, Jorge Orlando Cuéllar, Definição de Educação Ambiental. http://jararaca.ufsm.br/websites/unidadedeapoio/ página do curso de pós-graduação especialização em Educação Ambiental da UFSM, acessada no dia 04 de setembro de 2011 às 15h46min.

REIS, Lineu Belico dos. Geração de energia elétrica: tecnologia, inserção ambiental, planejamento, operação e análise de viabilidade. 3a edição. Barueri, SP: Editora Manole. págs.: 151-157 (2003).

SAUVÉ, Lucie. Uma cartografia das correntes em educação ambiental. In: . Educação Ambiental: pesquisa e desafios. Porto Alegre: Artmed, 2005. p. 17-44. 


\section{APÊNDICE A}

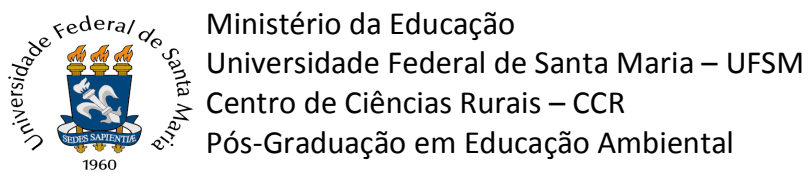

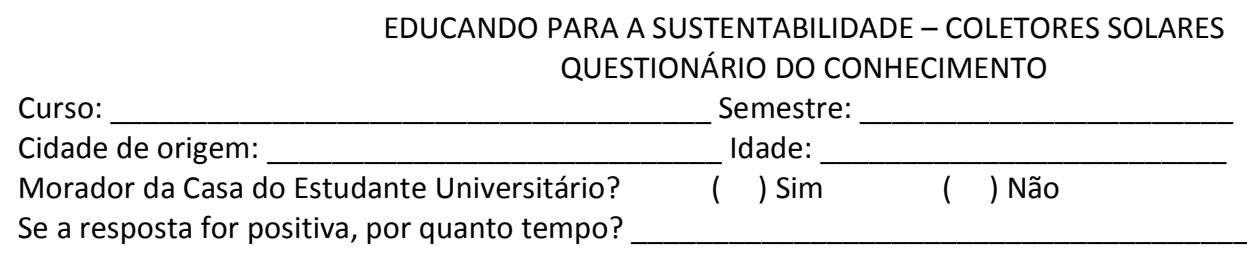

1- Qual a sua opinião sobre educação ambiental.

\begin{tabular}{lllll}
\hline \\
2- Você tem como prática economizar energia? & $($ ) Sim & $($ ) Não \\
3- Em caso afirmativo, quais as ações que você utiliza para economizar energia.
\end{tabular}

4- Em seu local de residência, você tem como prática utilizar lâmpadas econômicas?

$($ ) Sim ( ) Não

5- Em caso afirmativo, quais tipos de lâmpadas.

6- Em caso negativo, por que não?

7- Tem ideia do que sejam energias renováveis? $\quad(\quad) \operatorname{Sim} \quad(\quad)$ Não

8- Se a resposta for positiva, pode citar alguma?

9- Em sua opinião, quais formas de energia hoje utilizadas poderiam ser substituídas por alguma forma de energia renovável.

10- De acordo com o item número 8 quais poderiam ser utilizadas no estado do Rio Grande do Sul.

11- Deveria haver mais disciplinas sobre energias renováveis nos cursos da UFSM? Por quê? 
12- O que o Sol representa para você?

13- Já ouviu falar em utilização da energia solar? （ ) Sim （） Não

14- Se a resposta for positiva, qual a sua opinião a respeito do uso.

15- Se a resposta for negativa, por que não?

16- Você concordaria na utilização da energia solar na CEU como forma de aquecer a água do banho? ( ) Sim ( ) Não

17- Quanto tempo você costuma levar no banho?

18- Qual a sua opinião a respeito deste projeto piloto na UFSM.

19- Além da utilização da energia solar como aquecimento, você conhece mais alguma forma de utilização deste tipo de energia? ( ) Sim ( ) Não

20- Em caso afirmativo, poderia citar qual?

21- O folder explicativo sobre Energia Solar de alguma forma lhe ajudou a compreender o que é uma energia renovável e qual a sua utilização?

22- Qual a sua opinião sobre a divulgação da utilização de energias renováveis na UFSM?

Especializando: Eng ${ }^{\circ}$. Eletricista José Ayrton de Souza Borne Junior - PROINFRA.

Qualquer dúvida ligue: (55) 3220-9504 / 3220-8626 / 9167-4019. 
EDUCANDO PARA A SUSTENTABILIDADE Você sabia:

$\checkmark \quad$ Que o território brasileiro é um dos que mais recebe energia solar no mundo?

$\checkmark \quad$ Que a energia solar é uma energia sustentável, renovável, não poluente e que não agride o meio ambiente?

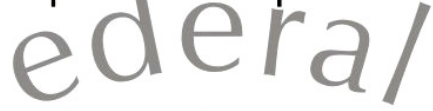

$\checkmark \quad$ Que um coletor solar pode aproveitaresta energia que vem do sol e aquecer a água, produzir eletricidade e como fonte de calor em processos industriais?

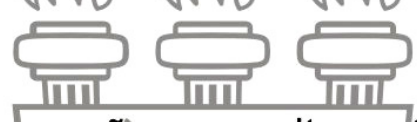

Porque não aproveitar esta energia? A UFSM irá dispanibilizar a você, que vai ocupar 9 novo módulo da Casa do Estudante Universitário (CEU), a possibitidade de experimentar e utilizar este $>$ tipo de energia para aquecer a água do seu banno.

$\geqslant$ Como?

Instalará um módulo coletor Sotar na cobertura do prédio e através de tubulaçấo levar a águáf quente até os apartamentos?

É uma oportunidade para VOCÊ, sim você, cooperar com o meio-ambiente e ser um pioneiro em um processo de sustentabilidade na UFSM.

Educação Ambiental: está na constituição, é um dever de todos e um direito do brasileiro de hoje e do amanhã.

Energia Solar - Uma UFSM Sustentável - Porque Não? Apoie essa ideia. 


\section{FUNCIONAMENTO DE UM COLETOR SOLAR}

Um Sistema de Aquecimento Solar [SAS] funciona como um trocador de calor. O Sol aquece o fluido que passa através das placas coletoras armazenando esta energia térmica em um tanque, também conhecido como "Boiler", entâo distribuindo esta água aquecida para o sistema de utilização. Existem dois tipos de sistemas: ativo, no qual é utilizada uma bomba hidráulica para circulação da água e o sistema passivo, no qual é utilizado o processo denominado termos sifão (a água aquecida diminui sua densidade e começa a se movimentar em direção ao reservatório, dando início aum processo natural de -

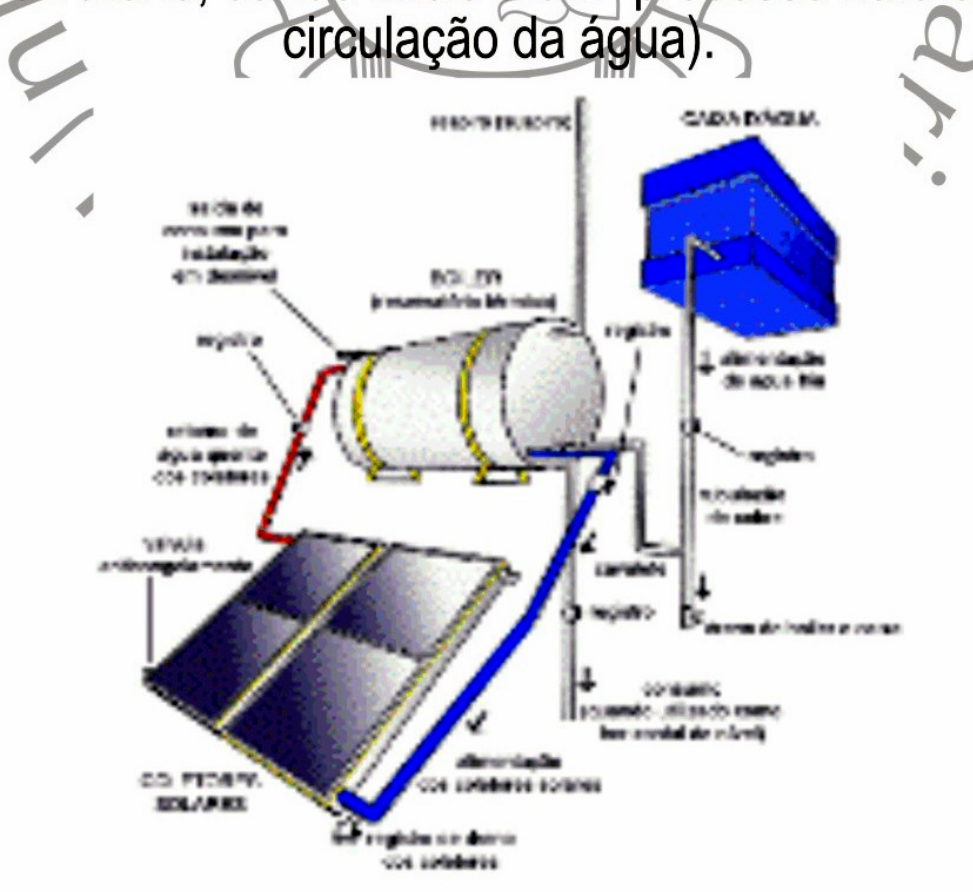

